\title{
Study of Steel Slag Filter Unit as a Secondary Treatment System for Removing Total Phosphorus from Textile Industry Wastewater
}

\author{
Nur Ain Nazirah Mohd Arshad ${ }^{1}$, R. Hamdan ${ }^{2 *}$ \\ ${ }^{1}$ Faculty of Civil Engineering and Built Environment, \\ Universiti Tun Hussein Onn Malaysia, 86400 Parit Raja, Batu Pahat, Johor, MALAYSIA \\ ${ }^{2}$ Micropollutant Research Centre, \\ Universiti Tun Hussein Onn Malaysia, 86400 Parit Raja, Batu Pahat, Johor, MALAYSIA \\ *Corresponding Author
}

DOI: https://doi.org/10.30880/ijie.2021.13.03.023

Received 05 January 2021; Accepted 13 May 2021; Available online 10 June 2021

\begin{abstract}
Eutrophication is one of the global concerned due to algae bloom in the natural surface water such as lakes and swamp area. Industrial effluent with incomplete treatment discharged has become one of the main culprits to this phenomenon. Approximately, $0.3-13 \mathrm{mg} / \mathrm{L}$ of total phosphorus can be found in the final discharge of industrial effluent showing that the existing treatment including an activated carbon filter (ACF) has limitation in polishing the phosphorus. Therefore, this 16 week of study has been designed to study the alternative treatment phosphorus removal at secondary stage to replace the tertiary treatment by using steel manufacturing by-product as filter media for effective phosphorus removal from the textile industry wastewater. Two units of lab-scale vertical steel slag filter (SSF) systems under aerated and unaerated conditions have been developed for this study. The samples were collected and analysed biweekly for selected parameters including $\mathrm{pH}$, alkalinity, DO and TP. The results obtained from this study show that the unaerated steel slag filter has a high efficiency of TP removal which ranged from $46 \%$ to $70 \%$ compared to the aerated SSF with removal efficiency ranged from $37 \%$ to $66 \%$. Besides, the existing ACF removal efficiency was ranged from $36 \%$ to $54 \%$. Thus, the use of steel slag in removing phosphorus from textile wastewater is possible with the used of both aerated and unaerated steel slag filter systems. Furthermore, the removal mechanism involved was likely to be precipitation and adsorption.
\end{abstract}

Keywords: Eutrophication, phosphorus removal mechanism, steel slag filter, textile wastewater

\section{Introduction}

Textile industry has emerged as one of the driven sectors in developing country revenue. The increment global population growth results to the higher textile demand from consumers, especially in countries such as Pakistan, India, China and Bangladesh [1]. Currently, China has become the world largest textile producer and exporter with total value of US $\$ 120$ billion, thus potentially stimulating its economic growth scenario [2]. Textile industries in Malaysia are slowly catching up as Malaysian Investment Development Authority (MIDA) have confirmed higher investment in the textiles and textile products industry, thus promoting the development of this industry at a large scale. Nonetheless, the glory of textile industry developments also carries concern toward our environment. The production of one ton of textile product consumes 200-350 $\mathrm{m}^{3}$ of water, which in returns generates massive amount of textile wastewater [3]. In Malaysia, textile industry has contributed to $22 \%$ of the wastewater generated after the food and poultry industries, making it the third 
largest contributor [4]. The textile industry is one of the significant manufacturing sectors that produce large volume of polluted and toxic wastewater with chemical oxygen demand (COD), nutrients, suspended solids and heavy metals along with another pollutant [5]. In the past years, nutrients, such as phosphorus, were commonly ignored since their effect was considered unimportant and attention was directed only on dye removal. Despite all the technology created and treatment system research in these past years, we were unable assure the complete removal of phosphorus from wastewater. Hence, it can be concluded that lack of information on the mechanisms of phosphorus in wastewater has become the barrier in achieving the effective treatment system of phosphorus.

\subsection{Phosphorus in Textile Wastewater}

Textile manufacturing involves a series of steps that uses chemical materials in the process. The chemical, such as dye and reducing agents such as sulphides, phosphates and acetic acids, sodium silicate and waxes used in the process making the wastewater high in toxicity [4]. The processes of kiering, bleaching and dyeing are the source of phosphorus inputs. However, the uses of detergent in cleaning process are the main culprit of phosphorus input due to the use of sodium phosphate and phosphoric acid [6]. Trisodium phosphate, potassium hydrogen phosphate trihydrate and dipotassium hydrogen phosphate were the chemicals included in synthetic dye that contribute to phosphorus concentration in the wastewater. The typical concentration of phosphorus present in textile effluent in Malaysia was from 1 to $13 \mathrm{Mg} / \mathrm{L}$ of $\mathrm{P}$, which was higher than the discharged permissible limit of $1 \mathrm{Mg} / \mathrm{L}$ as stated in the Standards for Effluent Discharge Regulations 2002 [7]. However, the permissible discharged limit was quite high, as Alamdari et al. [8] stated that even a slight rise of $0.1 \mathrm{Mg} / \mathrm{L}$ of $\mathrm{P}$ can promote growth of algae in the water body, which is also known as eutrophication. The excessive growth of algae utilises all the oxygen concentration in the water body, making it unsuitable for aquatic life [9]. Degradation of water quality was unavoidable thus adding water quality crisis to the list of problems. Therefore, it was required for manufacturer to implement effective treatment system for the treatment plant for complete removal of phosphorus from wastewater before being discharged. Phosphorus presences in textile wastewater were commonly ignored due to a high treatment cost, since phosphorus removal requires tertiary treatment stages. Furthermore, the colour of the wastewater is also concerning, since the effects can be seen with naked eye as it was aesthetically unappealing when it was released into the water body [10].

\subsection{Phosphorus Removal Treatment}

Phosphorus removals systems are commonly applied at tertiary treatment facility, hence, a huge additional cost is required to be taken under consideration. The common conventional and natural treatment methods are enhanced biological phosphorus removal (EBPR), waste stabilization pond (WSP) and constructed wetland, which have proven to be effective in treating phosphorus in the past years [11]. However, the excessive use of chemical in manufacturing process increase the toxicity of the wastewater, making these treatments become less effective in present time. The high volume of wastewater generated was also unable to be treated by the facilities, as all of the treatments listed above require large spaces. Although the effectiveness of the treatment can no longer be denied, these treatments have a few setbacks and are difficult to be implemented since the treatment systems require a large area, high maintenance and cost due to the large manpower required [11]. The cost of conventional wastewater treatment technologies was estimated between 10-450 US\$ per cubic meter of treated water [12]. Thus, the search of better phosphorus removal treatment was done in seeking more effective and affordable methods. Over time, myriad technologies were developed to contemplate the choices of solution for phosphorus removal treatment, such as the bio-treatment method. This method depends on microbes for the decomposition of phosphorus and other eutrophying substances [13]. This method can be considered as an economical method, but the long treatment time and large-scale treatment facilities are the disadvantages that need to be included in consideration [13]. The combined physico-chemical treatment method for phosphorus removal is also proven to be effective, but it is rarely employed due to excessive use of chemicals, high operational cost and complex sludge generation [14]. Therefore, the necessities of new alternative treatments were rushed with cost-saving features as the main idea and were believed to be industrial-sector friendly. Over the years, attentions were directed to the applications of rock filters which emerged as an alternative solution to remove nutrients with the use of by-products materials as filter media. Myriad materials have been explored as a filter adsorbent that exhibit excellent removals of the nutrient which. Among all the materials, a few materials such as coconut coir pith [16], limestone [17], fly ash [15] and iron oxide tailing [18] shows good removal when studied in domestic and synthetic wastewater. However, steel slag shows better removal of phosphorus due to the high presence of high metal ( $\mathrm{Ca}, \mathrm{Fe}, \mathrm{Mg}, \mathrm{Al})$ oxides, which promotes high phosphorus binding affinities [19-20]. Furthermore, the benefiting of steel slag as filter media contribute to waste utilization, as it is a by-product from steelmaking industry. The cost of materials can be reduced as it is an abundant and free material. Furthermore, aside from the presence of metal oxides in the materials, the removal of phosphorus is also closely related to $\mathrm{pH}$ value, the hydraulic retention rate (HRT), aeration, size of materials and temperature [19]. In addition, the most important factors that affect the removal were the $\mathrm{pH}$ of the wastewater.

\subsection{Phosphorus Removal Mechanism}


The effectiveness of the mechanisms depends on the application of the adsorbent and physical properties, such as particle size and hydraulic conductivity of the material. Appropriate $\mathrm{pH}$ also affects the removal mechanism of phosphorus, and must be taken into consideration when employing adsorbents as filter media. In sub-surface flow constructed wetland, the major removal mechanisms are adsorption and precipitation which perform quite similar to mechanisms in filters [20]. Both systems have adsorbents and wastewater to be in direct contact with each other allowing adsorption and precipitation to occur. Adsorption and precipitation process are the main mechanisms for phosphorus removal in rock filters [21], [22]. Multiple researchers have interpreted the adsorption onto metal oxides or oxyhydroxides on the surface of slag to be a significant phosphorus removal mechanism. Adsorption is a surface-based process where a film of adsorbate is created on the surface. The removal mechanism can be done with the presence of $\mathrm{Fe}, \mathrm{Ca}, \mathrm{Mg}$ and $\mathrm{Al}$, as these minerals adsorb inorganic ions, such as $\mathrm{PO}_{4}{ }^{3-}$, from the solution. Phosphate ions in the effluent are removed from solution by adsorption onto amorphous oxides or oxyhydroxides, which dominate the porous matrix and surface coating of the slag. However, in the presence of high $\mathrm{Ca}$, the adsorption occurs in an acidic condition.

Precipitation is a formation of sediment of substances in a liquid medium. The precipitation reactions from Fe and $\mathrm{Ca}$ salts in the presence of orthophosphate can be described as the formation of crystalline precipitate. The phosphate removal occurs through calcium phosphate precipitation at high $\mathrm{pH}$ in the presence of high calcium ion in the media [23]. The removal process occurs due to the precipitation of phosphate with exchangeable and dissolved $\mathrm{Ca}^{2+}$. The liberated $\mathrm{Ca}^{2+}$ from the exchange site or from the dissolution of $\mathrm{CaCO}_{3}, \mathrm{CaO}$ and $\mathrm{Ca}(\mathrm{OH})_{2}$ are preferably precipitated by phosphate in a neutral to alkaline solution [19]. Under neutral to acidic condition, phosphate removal is due to ion exchange between phosphate hydrolysis products $24(\mathrm{HPO}-\mathrm{HPO})^{-2}$ and the precipitation of the metallic salts of phosphate $\left(\mathrm{Al}^{3+}, \mathrm{Ca}^{2+}\right.$, $\left.\mathrm{Fe}^{3+}\right) \mathrm{Ca}^{2+}$, released by slag into solution, forms stable phosphate precipitates, such as hydroxyapatite $[\mathrm{Ca} 10(\mathrm{OH}) 2-$ $\left.\left(\mathrm{PO}_{4}\right) 6\right]$.The possible precipitates formed were hydroxyapatite, octacalcium phosphate, dicalcium phosphate dehydrate and amorphous calcium phosphate. Despite all the information obtained, the mechanism of removal remains unclear as the mechanism differs according to the type and strength of wastewater [22]. Besides, efforts were being made to remove the phosphorus at the secondary treatment system to avoid extra spending on tertiary treatment, where nutrients, especially phosphorus, were being removed [23-24]. Previous studies of steel slag filter system are mainly focussing in the application for domestic and synthetic wastewater. Therefore, the full application of steel slag filter system requires thorough understanding and research, especially for industrial sector application. Thus, to understand the removal mechanism of steel slag, this study was conducted for industrial application.

\section{Materials and Method}

\subsection{Lab-scale Vertical Aerated and Unaerated SSF systems}

Two units of lab-scale vertical aerated and unaerated steel slag filter systems were developed to study the removal mechanism of phosphorus that takes place in a slightly acidic to neutral $\mathrm{pH}$ range of wastewater under aerated and unaerated conditions. Both filters were installed for 16 weeks to function as secondary treatment stages at the existing treatment plant. The Perspex column filter with dimension of $150 \mathrm{~mm}$ inner diameter, $6 \mathrm{~mm}$ thickness and $400 \mathrm{~mm}$ total height have been installed at the selected textile wastewater treatment plant (see Fig. 1). The high Ca steel slag with the optimum sizes of 9.5 to $20 \mathrm{~mm}$ was used as filter media [25]. The influent for the filter is the primary treated wastewater which had been through the $\mathrm{pH}$ equalization and flocculation stages from the existing treatment plant with a slightly acidic to neutral $\mathrm{pH}$ range of 4.89-7.00. The $\mathrm{pH}$ values were monitored frequently to detect the variability of $\mathrm{pH}$ value throughout the study using a portable $\mathrm{pH}$ meter (HANNA HI-99310).

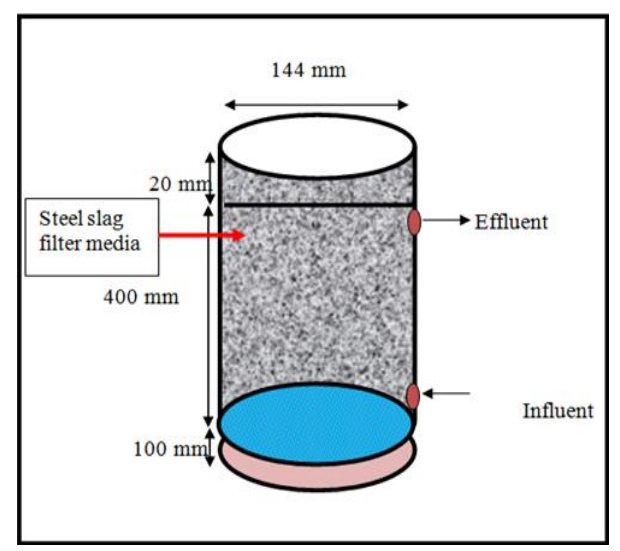

Fig. 1 - Filter column sizes and dimension

The inlets for the wastewater feed are located at the bottom of the filter column while the outlets are at the top of the filter column. Primary treated textile wastewater was pumped using peristaltic pumps at the base of the filter into the vertical column of ASSF and USSF so that the flow are in upward direction. In addition, ASSF was installed with air 
flow meters and aerated by using JUN Air Compressor as described in Fig. 2. The system was controlled by the required HLR and air flow rate that is $1.04 \mathrm{~m}^{3} / \mathrm{m}^{3} . \mathrm{d}$ and $0.25 \mathrm{~L} / \mathrm{min}$, respectively. Both filters were filled with the steel slag as filter media. The filters were run for 16 weeks at the selected textile industry located nearby UTHM.

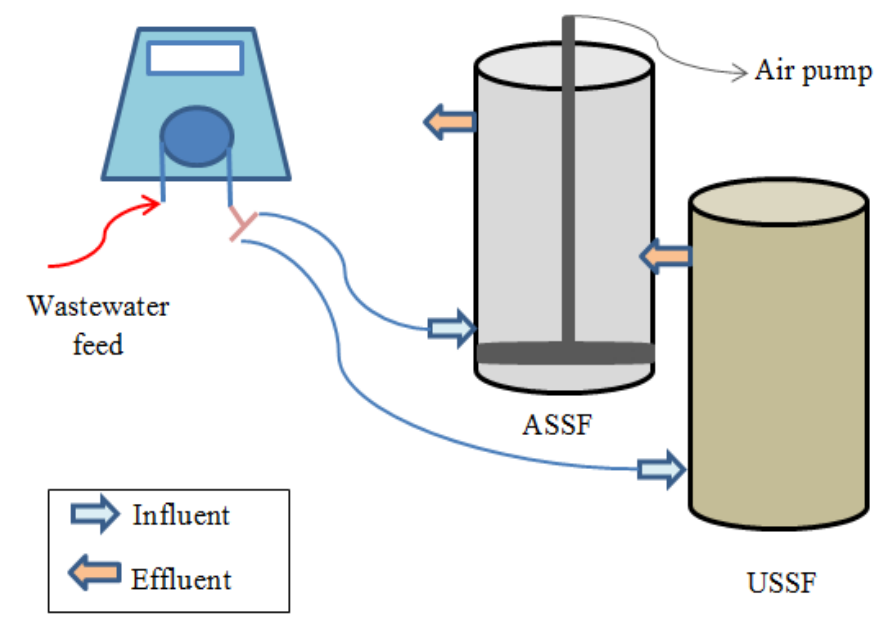

Fig. 2 - Schematic diagram of column filter for ASSF and USSF

\subsection{Wastewater Sampling and Analysis}

During the monitoring period, grab samples of the influent and effluent of the ASSF and USSF were collected and analysed biweekly, following Standard Methods for Water and Wastewater Examinations, for alkalinity (method no. 2330-B) and Total Phosphorus (4550P-E) [7]. Dissolved oxygen, was measured using in-situ YSI probe (model YSI Meter 6000) while $\mathrm{pH}$, and temperature were measured using a portable probe (model HANNA HI-99310).

\section{Discussion}

Samples from each filter system, USSF and ASSF was collected and analysed for the parameter of pH, alkalinity, DO and TP. Subsequently, a comparison study between both filters and the existing ACF as tertiary treatment was carried out to compare the effectiveness of removal at both stages. The $\mathrm{pH}$ condition and the alkalinity of the wastewater was closely related to the removal of phosphate ion. High alkalinity of wastewater provides more hydroxides ion for ion exchange for phosphorus removal through adsorption while precipitation of Ca-P related materials, such as $\mathrm{CaCO}_{3}$, were likely to occur at lower alkalinity and $\mathrm{pH}$ of wastewater [26]. The experimental results for the $\mathrm{pH}$ and alkalinity for ASSF, USSF and ACF were illustrated in Fig. 3. All filters had alkaline pH ranges of effluent, which are 7.91-9.12, 7.179.60 and 6.2-7.78 for ASSF, USSF and ACF respectively. This increase of pH of the solution in ASSF and USSF can be seen as the influent only lies on the $\mathrm{pH}$ range of 5.3-7. The $\mathrm{pH}$ increase was definitely contributed by the steel slag due to steel slag properties of high alkaline materials. The ASSF and USSF have higher effluent $\mathrm{pH}$ range compared to the ACF, since ACF effluent had undergone a complete treatment with $\mathrm{pH}$ adjustment while the ASSF and USSF are only underwent primary treatment. Therefore, the alkalinity of ASSF and USSF was expectedly higher than ACF. Both ASSF and USSF have similar graph trends on alkalinity. From week one until three, alkalinity in each filter increased, then fluctuated till week 11 and continued to decrease until week 16. The final alkalinity of ASSF and USSF over a fourmonth duration was $259.83 \mathrm{Mg} / \mathrm{L}$ as $\mathrm{CaCO}_{3}$ and $427.11 \mathrm{Mg} / \mathrm{L}$ as $\mathrm{CaCO}_{3}$ respectively, while $\mathrm{ACF}$ was $100 \mathrm{Mg} / \mathrm{L}$ as $\mathrm{CaCO}_{3}$. In high alkalinity condition, adsorption mechanisms are more dominant than precipitation mechanism. The hydroxide ion from $\mathrm{CaO}$ that dominates the surface of the slag undergoes ionic exchange with the hydroxyl group in the water, binding the $\mathrm{PO}_{4}^{-}$with $\mathrm{Ca}$ that is present on the surface.

The idea of aeration introduced in ASSF filter was to study the phosphorus removal mechanism in aerobic condition and to compare with USSF, which was anaerobic. Each filter shows a substantial difference in oxygen concentration. The DO for ASSF is higher than ACF, however, DO for USSF is lower than ACF, as can be observed in Fig. 4 below. The trends show that the DO for both ASSF and ACF are decreasing with a constant fluctuation over the number of days. Meanwhile, the DO of USSF is expected to be low since there is no aeration introduced in the filter to study the removal in anaerobic condition. The high peak of DO concentration is contributed by different properties of the wastewater introduced in the filter as the production of materials from the manufacture is daily and also the weathering condition. 

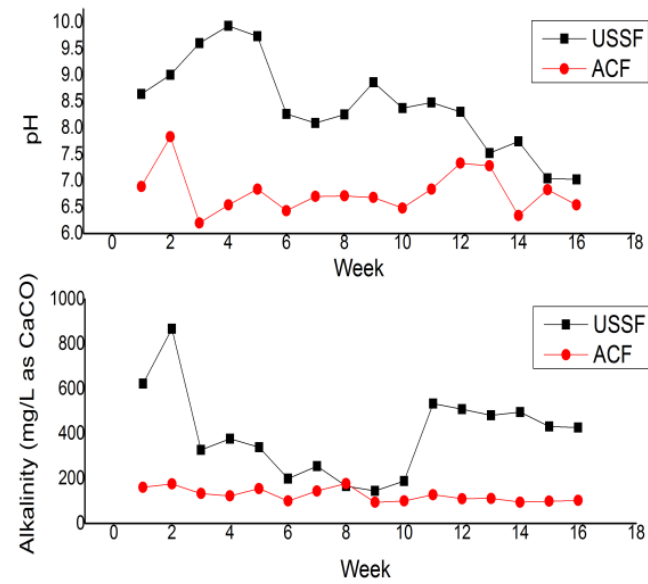

(a)

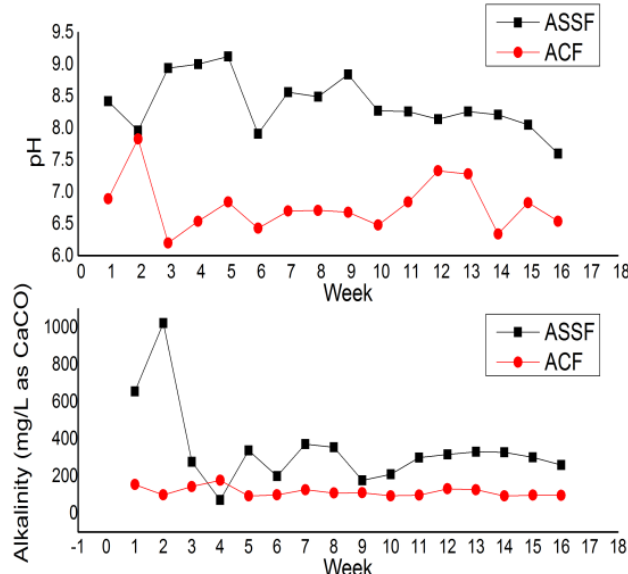

(b)

Fig. 3 - pH and Alkalinity of (a) USSF and (b) ASSF with ACF

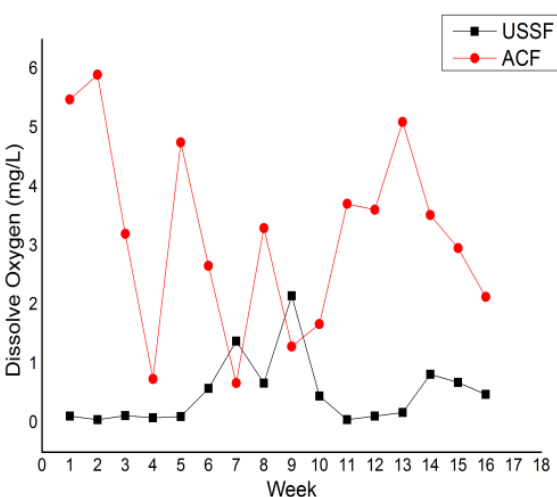

(a)

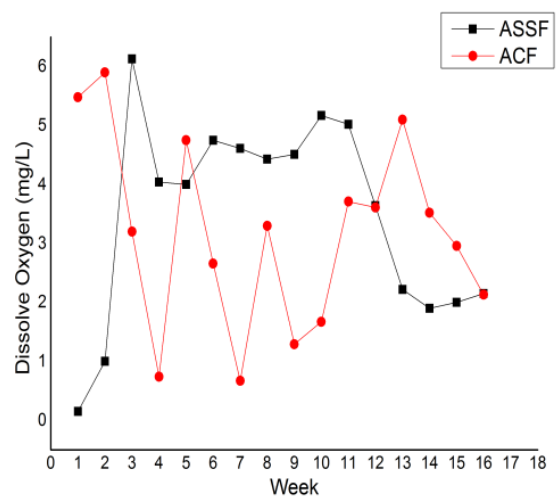

(b)

Fig. 4 - DO for (a) USSF and (b) ASSF with ACF

The efficiency of both filters was further compared to test the ability to remove the phosphate ion. The mechanism of removal is likely to be through precipitation mechanism at alkaline $\mathrm{pH}$ for USSF. According to Barca et. al, precipitation mechanism occurs when the liberated $\mathrm{Ca}^{2+}$ from the exchange site or from the dissolution of $\mathrm{CaCO}_{3}, \mathrm{CaO}$ and $\mathrm{Ca}(\mathrm{OH})_{2}$ were precipitated by phosphate in a neutral to alkaline solution [27]. Furthermore, findings from Hamdan et al. were also similar to Barca et al. when using synthetic wastewater as feed [28]. This result was also similar with both studies where the precipitation was dominant at alkaline $\mathrm{pH}$ for USSF due to the formation of the precipitate at the bottom of the filter. However, the precipitates were brown, which contradict with Hamdan et al. and Barca et al., since both of the research reported white crystalline precipitate. The brown precipitate was probably due to the reaction between ferric oxide present in the slag, which indicates the reaction between the liberated $\mathrm{Fe}^{2+}$ or the dissolution of $\mathrm{Fe}_{2} \mathrm{O}_{2}$ and $\mathrm{Fe}(\mathrm{OH})_{2}$ from the steel slag and phosphorus in the wastewater [9]. On the other hand, brown layer of adsorbate was also found on the surface of the slag formed in ASSF, most likely due to the binding of $\mathrm{Fe}^{2+}$ present in the steel slag surfaces with $\mathrm{PO}_{4}{ }^{3-}$ in the wastewater. Nonetheless, both filters showed promising results in removing phosphorus, even if they were at a higher $\mathrm{pH}$. Based on the efficiency graph illustrated in Fig. 5, USSF shows fluctuation on the removal efficiency from week one to eight, after which it increases until week ten. Starting from here, the efficiency decreases until week 16. The trend of the removal efficiency of the USSF is difficult to determine, since the influent value is inconsistent. On the other hand, filter ASSF shows better removal trend as the removal efficiency increases from week two until week ten, where the highest removal efficiency was reported. Starting from here, the efficiency decreases until week 16 . ASSF shows excellent removals of phosphorus, however, USSF performs slightly better than the ASSF as the removal efficiency is higher than ASSF. The removal efficiency of ASSF was in the range of $37 \%$ to $66 \%$ while USSF was in the range of $46 \%$ to $70 \%$. This shows that the suitable condition for phosphorus removal is anaerobic in a high Ca steel slag. Apart from this, the aeration was not introduced in the USSF, making it able to remove phosphorus better than ASSF due to undisturbed condition from aeration. The vibration from the aeration bubble provides disturbance to the adsorption where the vibration ensures that the matter is released from its attached surface [29]. Aside from that, the removal efficiency for ASSF and USSF filters were compared with ACF that was installed in the existing treatment, as illustrated in Fig. 5. The ACF removed phosphorus at an efficiency rate of 35\% to 54\%, which are the lowest compared to USSF and ASSF. ACF is the existing system of the treatment plant which undergoes primary, secondary and tertiary treatment. 
The inefficient removal of phosphorus by ACF shows that the phosphorus was not completely treated before the wastewater was being discharged. Based on the figures below, the USSF removes phosphorus better than ASSF and ACF with excellent efficiency. Meanwhile, ASSF and ACF have similar fluctuation trends, however, ASSF performs slightly better than ACF. Nonetheless, all filters were able to remove phosphorus.

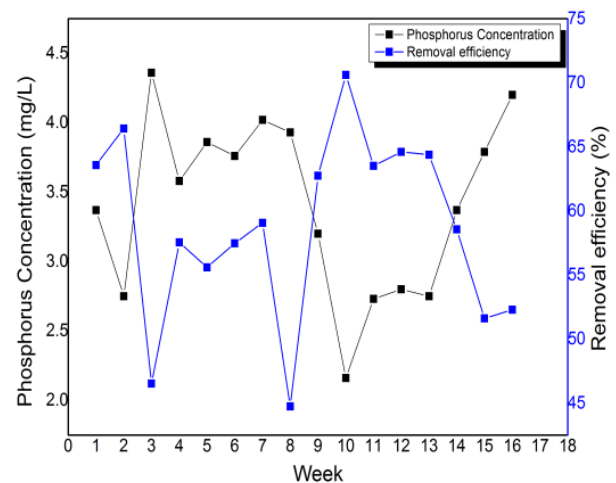

(a)

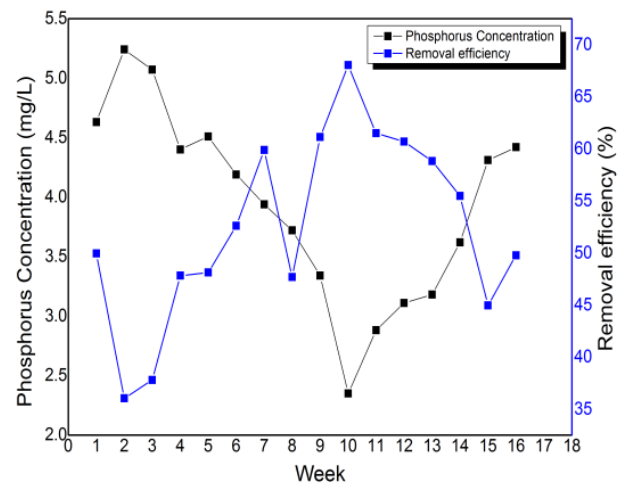

(b)

Fig. 5 - Efficiency of phosphorus removal in (a) USSF and (b) ASSF

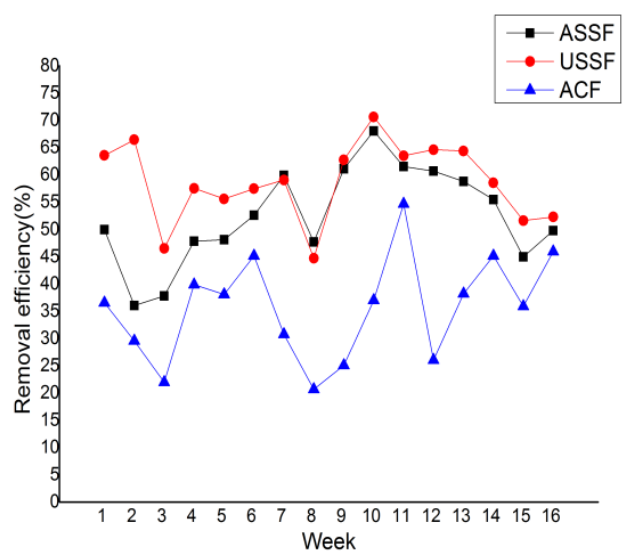

Fig. 6 - Efficiency of phosphorus removals in ASSF, USSF and ACF

\section{Conclusion}

The overall performance of the filters was efficient in removing phosphorus. DO content could be achieved higher in the aerated SSF compared to the unaerated SSF. However, in terms of phosphorus removal, unaerated SSF outperformed compared to aerated SSF. In addition, alkaline condition in the unaerated SSF system favour the phosphorus removal as the removal efficiency was found to be higher compared to the aerated SSF, with a range of $46 \%$ to $70 \%$. Furthermore, the removal mechanism that takes place in both SSF systems was dominantly through adsorption on steel slag surface. Based on the results obtained, it can be concluded that the $\mathrm{pH}$ value plays an important role in removing phosphorus due to the high $\mathrm{pH}$ value in the unaerated SSF. In contrast, ACF showed the lowest removal compared to the SSF systems. Thus, the use of steel slag in removing phosphorus from textile wastewater is possible. Since USSF and ASSF performed better that ACF, this shows that the removal of phosphorus is possible at secondary stage treatment with a proper primary and secondary treatment design.

\section{Acknowledgement}

We are extremely grateful to all our funders: Universiti Tun Hussein Onn Malaysia under GPPS (Vot H451) and Anfi Industries Sdn. Bhd. for providing textile wastewater sample. Last but not least; special thanks go to Antara Steel Sdn Bhd, for kindly providing us high Ca steel slag for this project.

\section{References}


(C) Universiti Tun Hussein Onn Malaysia Publisher's Office

\section{IJIE}

Journal homepage: http://penerbit.uthm.edu.my/ojs/index.php/ijie ISSN : 2229-838X e-ISSN : 2600-7916
The International

Journal of

Integrated

Engineering

[1] Bilińska L., Gmurek M. \& Ledakowicz S. (2016). Comparison between industrial and simulated textile wastewater treatment by AOPs-Biodegradability, toxicity and cost assessment. Chemical Engineering Journal, 306, 550-559

[2] Lin J., Greydanus B., Balta S., \& Vlad M. (2015). Toward resource recovery from textile wastewater: dye extraction, water and base/acid regeneration using a hybrid NF-BMED process. ACS Sustainable Chemistry and Engineering, 3(9), 1993-2001

[3] Wang Z., Xue M., Huang K. \& Liu Z. (2011). Textile dyeing wastewater treatment. Advances in Treating Textile Effluent, 5, 91-116

[4] Yaseen D. A. \& Scholz M. (2019). Textile dye wastewater characteristics and constituents of synthetic effluents: A critical review. International Journal of Environmental Science and Technology, 16(2), 1193-1226

[5] Jegatheesan V., Pramanik B. K., Chen J., Navaratna D., Chang C. Y. \& Shu L. (2016). Treatment of textile wastewater with membrane bioreactor: A critical review. Bioresource Technology, 204, 202-212

[6] Meerbergen K., Van Geel M., Waud M., \& Willems K. A. (2017). Assessing the composition of microbial communities in textile wastewater treatment plants in comparison with municipal wastewater treatment plants. Microbiology Open, 6(1), e00413

[7] Dey S. \& Islam A. (2012). A review on textile wastewater characterization in Bangladesh. Resources and Environment, 5(1), 15-44

[8] Alamdari A. \& Rohani S. (2007). Phosphate recovery from municipal wastewater through crystallization of calcium phosphate. The Pacific Journal of Science and Technology, 8(1), 27-31

[9] Hamdan R., Arshad N. A. N. M. \& Ahmad S. Z. N. (2018). The effects of PO 4 3-removal from aqueous solution with varied concentrations of metal oxides in steel slag filter system. Journal of Physical Science, 29, 71-80

[10] Mohd Razi M. A., Mohd Hishammudin M. N. A., \& Hamdan R. (2017). Factor affecting textile dye removal using adsorbent from activated carbon: A review. MATEC Web of Conferences, 103, 06015

[11] Hamdan R. \& Mara D. D. (2014). Removal of nitrogen and phosphorus from waste stabilization pond effluents using aerated blast-furnace-slag filters. WIT Transaction on Engineering Sciences, 88,719-726

[12] Ali I., Asim M. \& Khan T. A. (2012). Low cost adsorbents for the removal of organic pollutants from wastewater. Journal of Environmental Management,113, 170-183

[13] Fehintola J., Amoko E., Obijole O., Bolorunduro K. A. \& Oke I. (2016). Mechanisms and modelling phosphate removal from textile wastewaters by chemical coagulation. Direct Research Journal of Chemistry and Material Science, 4, 1-13

[14] Nawaz M. S. \& Ahsan M. (2014). Comparison of physico-chemical, advanced oxidation and biological techniques for the textile wastewater treatment. Alexandria Engineering Journal, 53(3), 717-722

[15] Hegazi H. A. (2013). Removal of heavy metals from wastewater using agricultural \& industrial wastes as adsorbents. HBRC Journal, 9(3), 276-282

[16] Adegoke K. A. \& Bello O. S. (2015). Dye sequestration using agricultural wastes as adsorbents. Water Resources and Industry, 12, 8-24

[17] Nilsson C., Lakshmanan R., Renman G. \& Rajarao G. K. (2013). Efficacy of reactive mineral-based sorbents for phosphate, bacteria, nitrogen and TOC removal-column experiment in recirculation batch mode. Water Research, 47(14), 5165-5175

[18] Blanco I., Molle P., de Miera L. E. S. \& Ansola G. (2016). Basic oxygen furnace steel slag aggregates for phosphorus treatment. Evaluation of its potential use as a substrate in constructed wetlands. Water research. 89, 355-365

[19] Barca C., Troesch S., Meyer D., Drissen P., Andreìs Y. \& Chazarenc F. (2013). Steel slag filters to upgrade phosphorus removal in constructed wetlands: Two years of field experiments. Environmental Science and Technology., 47(1), 549-556

[20] Vymazal J. (2010). Constructed Wetlands for Wastewater Treatment. Water, 2, 530-549

[21] Hamdan R. \& Mara D. (2013). Study of in-filter phosphorus removal mechanisms in an aerated blast furnace slag. International Journal of Research in Engineering and Technology., 2(8), 130-136

[22] Klimeski A., Chardon W. J., Turtola E. \& Uusitalo R. (2012). Potential and limitations of phosphate retention media in water protection: A process-based review of laboratory and field-scale tests. Agricultural and Food Science., 21(3), 206-223

[23] Ugurlu A. \& Salman B. (1998). Phosphorus removal by fly ash. Environment International., 24(8), 911-918, 1998.

[24] De Gisi S., Lofrano G., Grassi M \& Notarnicola,M. (2016). Characteristics and adsorption capacities of low-cost 
sorbents for wastewater treatment: A review. Sustainable Materials and Technologies., 9, 10-40

[25] Afnizan W. M. W., Hamdan R. \& Othman N. (2016). Study of the maximum uptake capacity on various sizes of electric arc furnace slag in phosphorus aqueous solutions. IOP Conference Series: Materials Science and Engineering, 136(1), 012060

[26] American Public Health Association (2017). American Water Works Federation and Water Environment Federation. Standard Methods for the Examination of Water and Wastewater

[27] Hamdan R. \& Mara D. (2013). Aerated blast-furnace-slag filters for the simultaneous removal of nitrogen and phosphorus from primary facultative pond effluents. International Journal of Integrated Engineering, 5(1), 17-22

[28] Barca C., Meyer D., Liira M., Drissen P., Comeau Y., Andrès Y. \& Chazarenc F. (2014). Steel slag filters to upgrade phosphorus removal in small wastewater treatment plants: removal mechanisms and performance. Ecological engineering, 68, 214-222

[29] Ahmad S. Z. N., Hamdan R., Mohamed W. A. W., Othman N., Zin N. S. M. \& Musa S. (2017). Comparisons Study of phosphate removal in unaerated and aerated high calcium steel slag filter system of different $\mathrm{pH}$ feed. MATEC Web of Conferences, 103, 06018

[30] Zhu L., Li X., Zhang C. \& Duan Z. (2017). Pollutants' release, redistribution and remediation of black smelly river sediment based on re-suspension and deep aeration of sediment. International Journal of Environmental Research and Public Health, 14(4), 374 